\title{
The Dark Side of the MBTI: Psychological Type and Interpersonal Derailers
}

\author{
Adrian Furnham ${ }^{1,2}$, John Crump ${ }^{1}$ \\ ${ }^{1}$ Research Department of Clinical, Educational and Health Psychology, University College London, \\ London, UK \\ ${ }^{2}$ BI Norwegian Business School, Oslo, Norway \\ Email: a.furnham@ucl.ac.uk
}

Received December $1^{\text {st }}, 2013$; revised January $2^{\text {nd }}, 2014$; accepted February $3^{\text {rd }}, 2014$

\begin{abstract}
Copyright (c) 2014 Adrian Furnham, John Crump. This is an open access article distributed under the Creative Commons Attribution License, which permits unrestricted use, distribution, and reproduction in any medium, provided the original work is properly cited. In accordance of the Creative Commons Attribution License all Copyrights ( 2014 are reserved for SCIRP and the owner of the intellectual property Adrian Furnham, John Crump. All Copyright $@ 2014$ are guarded by law and by SCIRP as a guardian.
\end{abstract}

Over 4000 British adults completed the Hogan Development Survey (HDS) (Hogan \& Hogan, 1997) which measures eleven potential derailment behaviours ("dark side” traits) based on the personality disorders and the Myers-Briggs Type Indicator (Briggs \& Myers, 1987) a famous measure of "normal” personality functioning. In all, five of the eleven "dark side" traits were correlated with the Extraversion-Introversion dimensions, none with Sensing-Intuition, seven with Thinking-Feeling and four with the Judging-Perceiving scale. Correlations were modest. Regressions with the four MBTI scales as criterion variables showed nine of the HDS factors were related to the T-F scale and accounted for $12 \%$ of the variance. Thinking types tended to be Sceptical, Reserved and Diligent. Overall correlations were low suggesting the MBTI assesses some aspects of dark side traits.

Keywords: MBTI; Psychological Type; Derailers; Personality Disorders

\section{Introduction}

This study looked at the "dark side" personality correlates of the Myers Briggs Type Indicator (MBTI) (Briggs \& Myers, 1987). The concept of "dark side" traits has come to be associated with measures of subclinical personality disorders or derailers (Hogan \& Hogan, 2001; Moscoso \& Salgado, 2004). Dark side traits measured by the Hogan Development Survey (HDS) have been investigated recently in a large number of studies (De Fruyt, Wille, \& Furnham, 2013; Furnham, Hyde, \& Trickey, 2013; Harms, Spain, \& Hannah, 2011; Zibarras, Port, \& Woods, 2008).

This study is part of a programmatic series of concurrent and discriminant validity studies that attempt to investigate the relationship between "normal” personality traits (usually the Big Five but here the Big Four) and the personality disorders. There are various studies and reviews in this area but none have used the very popular MBTI preferring to look at Big Five correlates of disorders (Samuel \& Widiger, 2008; Widiger, 2011).

\section{The MBTI}

The most widely known and used personality test is the Myers Briggs Type Indicator (Paul, 2004). It is based on Jungian theory and is a four factor model which allows people to be described by four letters (e.g. ENTJ, ISFP) representing their particular type. The scale yields eight scores (one for each type) which can be considered on four typological opposites (i.e. Introversion or Extraversion).
According to McCrae and Costa (1989), the MBTI is unusual among personality assessment devices for three reasons: it is based on a sophisticated and established theory (Jungian); it purports to measures types rather than traits specified on a continuous scale; and it is widely used to explain individuals' personality characteristics not only to professionals but also to the individuals themselves, as well as their co-workers, friends, and families. They also point out its limitations; the original Jungian concepts are distorted and even contradicted; there is no bi-modal distribution of preference scores; studies using the MTBI have frequently not confirmed either the theory or the measure.

Various studies have looked at the location of the MBTI in personality factor space as well as the relationship between the MBTI and the Big Five factors. Saggino and Kline (1996) looked at correlations between the MBTI and Cattell's 16PF as well as Eysenck's EPQ. Their factor analysis of the MBTI yielded five, not four, factors. They argued the EI (Extraversion-Introverson) dimension is clear, but the TF (ThinkingFeeling) dimension is "not sufficiently pure" because it loads onto different factors.

McCrae and Costa (1989) found the four MBTI indices measures aspects of four of the Big 5 dimensions of personality. More specifically, they found that EI was correlated with Extraversion, SN with Openness, TF with Agreeableness and JP (Judging-Perceiving) with Conscientiousness. These results were replicated by MacDonald, Anderson, Tsagarakis and Holland (1994). Furnham (1996) also provided evidence supporting these results, but found further that Neuroticism was corre- 
lated to both EI and TF. The highest correlations were between EI and Extraversion facets of Gregariousness, Warmth, and Positive emotions, between SN and Openness facets Ideas, Fantasy and Aesthetics, between TF and Agreeableness facets of Tender-mindedness, Trust and Altruism, between JP and Conscientiousness facets of Order, Deliberation and Self-Discipline and between EI and Neuroticism facets of Self-consciousness, Depression and Vulnerability (Neuroticism). Furnham, Moutafi and Crump (2003) found similar results.

There have been a number of studies that have related the Big Five personality traits to the personality disorders suggesting significant overlap (Samuel \& Widiger, 2008; Bastiaansen, Rossi, Schotte, \& De Fruyt, 2011). Some studies have related the MBTI to dark side traits which is the focus of this paper (Janowsky, Morter, \& Hong, 2002). It should be noted however that proponents of the MBTI insist that the measure was never designed to, nor does it measure "pathology" or mental illness of any form (Quenk, 2009). The line has always been "gifts differing" and that there is no right or wrong, better or worse type (Myers \& Myers, 1990). However, the question remains as to the correlates of the various $16 \mathrm{MBTI}$ types and whether this indicates that some of the types and dimensions are clearly related to psychopathology of one sort or another. This study, in part, tests this assumption: i.e., that MBTI scores are not measures of pathology

\section{The Dark Side}

There are various self-report measures available to assess Personality Disorders (Morey, Waugh, \& Blashfield, 1985; Moscoso \& Salgado, 2004; Widiger \& Coker, 2001). This study used the Hogan "dark side" measure (HDS) which is now extensively used in organisational research and practice to measure personality disorders in the "normal population" (De Fruyt et al., 2009, 2011; Furnham \& Crump, 2005; Hogan \& Hogan, 1997, Zibarras, Port, \& Woods, 2008). It is one of the tests that measures all the disorders from a non-clinical perspective with evidence of good psychometric qualities (Furnham, Trickey, \& Hyde, 2012). The scale measures dysfunctional interpersonal tendencies that may be debilitating for people over time and thus increasing their likelihood of derailing. Its aim is partly to help selectors and individuals themselves diagnose how they typically react under work stress. It has the advantage of being psychometrically valid (Hogan, Hogan, \& Warrenfeltz, 2007); of measuring all the personality disorders and being appropriate for a "normal" population.

The Hogan Development Survey (HDS) was explicitly based on the DSM-IV-TR Axis II Personality Disorder (American Psychiatric Association, 1994, 2000). The HDS focuses only on the core construct of each disorder from a dimensional perspective (Hogan \& Hogan, 2001: p. 41). Using the concepts of Horney (1950) they categorised the dysfunctional interpersonal tendencies into 3 categories: "Moving Against People" (aggression and manipulation); "Moving Away from People" (withdrawal and intimidation); and "Moving Toward People" (compliance and ingratiation).

\section{This Study}

Very few published studies have related MBTI traits to personality disorders or related measures (Pierson, 2007). An exception is the study by Coolidge, Segal, Hook, Yamazaki and
Elliot (2000) who tested a convenience sample of 332 young Americans. They completed a 225 item self-report measure of the personality disorders (CATI) (Coolidge, 1984) and the MBTI. Many correlations were significant. Correlational results (with $r>$.25) showed the E-I scale (with Introversion being high) correlated positively significantly with Avoidant, Obsessive-Compulsive, Paranoid, Schizoid and Schizotypal and negative with Histrionic. The $\mathrm{S}-\mathrm{N}$ dimensions showed it to be positively correlated with Borderline. The T-F scale was significantly negatively correlated with Antisocial, Paranoid, Sadistic, Schizoid and Schizotypal disorder. Finally, there were two significant correlations with the J-P dimension: Antisocial (positive) and Obsessive-Compulsive (negative). Two disorders had correlations with all four dimensions: Schizotypal people had an INTP profile whereas Obsessive compulsives had an ISTJ profile. Antisocial and Sadistic people were NTP whereas Passive-Aggressive people were INP. The authors noted “....it appears that the MBTI may have heuristic value in understanding personality disorders” (p. 35).

This study extends the above study in two ways. First, it has a population 15 times the size of the above study using a much more representative adult sample. Second, it uses the HDS rather than the CATI which appears to be a much better psychometrised instrument.

Neuroticism is a central component in the personality disorders but not assessed in the MBTI. Thus it was predicted that overlap would not be considerable between these two measures.

It was predicted (H1) that of the four MBTI dimensions, the T-F dimension will be most closely related to the HDS scales. This is because previous studies linking the MBTI and Big Five measures have shown the Feelings scale to be most closely linked Domain Neuroticism and its facets. Next, that the HDS factors Reserved and Colourful and Diligent (H2) would be most related to the MBTI factor extraversion-introversion, while the factors of Diligent and Mischievous (H3) would be related to the judging-perceiving MBTI dimensions (Furnham \& Crump, 2005).

\section{Method}

\section{Participants}

In total 4812 British working adults took part in this study of which 948 were females and 3864 males. Their mean age was 32.53 years $(\mathrm{SD}=8.14$ years) with the range being between 23 and 65 years. In all $70 \%$ were between 30 and 50 years. They were nearly all (over 95\%) graduates and in middle class occupations with English as their mother tongue.

\section{Measure}

Myers-Briggs Type Indicator-Form G (MBTI: Briggs \& Myers, 1987). The Myers-Briggs indicator is a Jungian-based inventory that uses a paper-and-pencil self-report format. It is composed of 94 forced-choice items that yield scores on each of the eight factors as well as the famous four dimensions: Introversion-Extraversion, Sensation-Intuition, Thinking-Feeling and Judging-Perceiving. Respondents are classified into one of 16 personality types based on the largest score obtained for each bipolar scale (e.g. a person scoring higher on Introversion than Extraversion, Intuition than Sensation, Feeling than Thinking and Judging than Perceiving would be classified as an Introverted Intuitive Feeling Judging). The test provides linear 
scores on each dimension which are usually discussed in terms of types based on cut-off scores. Thus the Extraversion-Introversion dimension has a normal distribution with high scores being considered Extraverted and low Introverted (See Table 1). The Myers-Briggs Type Indicator has been the focus of extensive research and substantial evidence has accumulated suggesting the inventory has satisfactory concurrent and predictive validity and reliability (Furnham \& Stringfield, 1993).

Hogan Development Survey (Hogan \& Hogan, 1997) consists of 154 items that are concerned with how the respondent typically interacts with family, friends and co-workers. There are 11 scales, each grouping 14 items. Higher scores on most scales correspond to an increased risk on specific interpersonal problems in the workplace. Numerous factor analyses have show three higher order factors in the scale labelled moving toward, away from and against others. (Furnham et al., 2012, 2013). The HDS has been cross-validated with the MMPI personality disorder scales. Correlations $(n=140)$ range from .45 for Antisocial to .67 for Borderline (Hogan \& Hogan, 2001). Fico, Hogan and Hogan (2000) report coefficient alphas between .50 and .70 with an average of .64 and test-retest reliabilities $(\mathrm{n}=60)$ over a three-month interval ranging from .50 to .80 , with an average of .68 There were no mean-level differences between sexes, racial/ethnic groups, or younger versus older persons (Hogan \& Hogan, 2001). Various studies have used the HDS and have shown it to be a robust, reliable and valid instrument (Carson, Shanock, Heggestad, Andrew, Pugh, \& Walter, 2012; De Fruyt et al., 2009; Furnham, 2006; Furnham \& Crump, 2005; Harms, Spain, \& Hannah, 2011; Khoo \& Burch, 2008; Rolland \& De Fruyt, 2003).

\section{Procedure}

Participants were tested by a British based psychological consultancy over a 10-year period. Each participant was given personal feedback on their scores. They were nearly all employed as middle to senior managers in British companies. They took this test as part of an assessment exercise. Inevitably this could have affected their results because of issues such as impression management and dissimulation. However, the HDS has a scale (called the validity scale) which can be used to control for this problem.

\section{Results}

Table 1 shows the correlations (with Bonferroni corrections) between the four MBTI and the eleven HDS scores. The results provide support for all the hypotheses. With a very big N, correlations $r>.05$ are significant so those $r>.08$ are highlighted in bold. The first column indicated that those who scored high on MBTI Extraversion tended to be low on Cautious, and Reserved but high on Bold, Mischievous and Colourful. Essentially none of the dark side measures correlated with the MBTI Sensing-Intuitive (SN) dimension. The results from the Thinking-Feeling Dimension were interesting. Those with a high Thinking scores tended to be high on Sceptical, Reserved, Bold, Mischievous and Diligent but low on Cautious and Dutiful. The final set of correlations indicated that the higher the participant scored on the MBTI Judging scale the lower they scored on Mischievous, Colourful, and Imaginative but higher on Diligent.

Table 2 shows a finer grained analysis. Here, partial correlations were computed with sex and age and reliability (impression management) partialled out, and with the eight scales. Eight sets of correlations were $>.30$. The highest correlations showed Extraverts were low on Reserved and high on Colourful, with Introverts being the opposite. Equally Judging types tended to be high and Perceiving types low on Diligence.

Table 3 shows the results from the step-wise multiple regressions. First, sex and age were entered then the eleven dark side variables. Regression of the predictor variables onto the MBTI Extraversion-Introversion (E-I) dimension showed three factors accounted for $5 \%$ of the variance. Extraverts were likely to be less Reserved and more Colourful as well as scoring higher on the Social Desirability scale. With the S-N scale as the criterion variable it seemed four "dark side" were involved but that they only accounted for $1 \%$ of the variance.

Table 1.

Means and Standard Deviations for the two scales and correlations. Correlations $r>.08(p<.001)$ are shown in bold.

\begin{tabular}{|c|c|c|c|c|c|c|c|}
\hline & & & & EI & SN & $\mathrm{TF}$ & JP \\
\hline & & & $\mathrm{x}$ & 22.84 & 22.19 & 27.41 & 23.36 \\
\hline & $\mathrm{x}$ & SD & SD & 14.87 & 14.60 & 15.76 & 14.54 \\
\hline 1. Excitable & 3.09 & 2.61 & & -05 & -01 & -04 & -02 \\
\hline 2. Sceptical & 4.52 & 2.49 & & -03 & 00 & 15 & 02 \\
\hline 3. Cautious & 3.36 & 2.78 & & -12 & 03 & -14 & 06 \\
\hline 4. Reserved & 4.63 & 2.23 & & -18 & 01 & 13 & 02 \\
\hline 5. Leisurely & 4.86 & 2.19 & & -05 & 00 & 00 & 03 \\
\hline 6. Bold & 7.34 & 2.81 & & 10 & -03 & 11 & 02 \\
\hline 7. Mischievous & 6.95 & 2.50 & & 09 & -03 & 08 & -15 \\
\hline 8. Colourful & 7.85 & 2.99 & & 18 & 02 & 00 & -08 \\
\hline 9. Imaginative & 5.54 & 2.37 & & 06 & 00 & -02 & -09 \\
\hline 10. Diligent & 8.89 & 2.45 & & -02 & -05 & 08 & 14 \\
\hline 11. Dutiful & 7.04 & 2.05 & & -02 & -02 & -18 & 02 \\
\hline 12. Social Desirability & 5.18 & 1.47 & & 03 & 00 & 01 & 03 \\
\hline
\end{tabular}

$\mathrm{N}=3208$; Correlations in bold are $p<.001$ Bonferonni corrected. 
Table 2.

Partial correlations between each of the eight personality measures and the 11 dark side variables.

\begin{tabular}{|c|c|c|c|c|c|c|c|c|}
\hline & E & I & S & $\mathrm{N}$ & $\mathrm{T}$ & $\mathrm{F}$ & $\mathrm{J}$ & P \\
\hline 1. Excitable & -.16 & .10 & -.00 & -.06 & -.05 & .01 & -.05 & -.02 \\
\hline 2. Sceptical & -.05 & .05 & .10 & -.10 & .19 & -.11 & .04 & -.03 \\
\hline 3. Cautious & -.48 & .50 & .17 & -.15 & -.13 & .12 & .11 & -.10 \\
\hline 4. Reserved & -.58 & .59 & .10 & -.08 & .14 & -.09 & .05 & -.04 \\
\hline 5. Leisurely & -.23 & .23 & .10 & -.08 & .01 & .00 & .02 & -.01 \\
\hline 6. Bold & .19 & -.21 & -.11 & .09 & .12 & -.10 & -.05 & .06 \\
\hline 7. Mischievous & .30 & -.34 & -.27 & .27 & .10 & -.04 & -.34 & .36 \\
\hline 8. Colourful & .49 & -.52 & -.28 & .28 & .01 & .02 & -.20 & .22 \\
\hline 9. Imaginative & .20 & -.22 & -.34 & .33 & .01 & .05 & -.20 & .22 \\
\hline 10. Diligent & -.08 & .10 & .30 & -.30 & .09 & -.09 & .52 & -.54 \\
\hline 11. Dutiful & -.05 & .06 & .20 & -.21 & -.17 & .13 & .14 & -.16 \\
\hline 12. Social Desirability & -.00 & .01 & .00 & -.01 & -.01 & .04 & .03 & -.03 \\
\hline
\end{tabular}

$\mathrm{N}=$ 3014; Correlations in bold are $p<.001$ Bonferonni corrected.

Table 3.

Partial correlations between each of the eight personality measures and the 11 dark side variables.

\begin{tabular}{|c|c|c|c|c|c|c|c|c|}
\hline & \multicolumn{8}{|c|}{ Myers-Briggs Scale } \\
\hline & \multicolumn{2}{|c|}{ EI } & \multicolumn{2}{|c|}{ SN } & \multicolumn{2}{|c|}{ TF } & \multicolumn{2}{|c|}{ JP } \\
\hline & Beta & $\mathbf{t}$ & Beta & $\mathbf{t}$ & Beta & $\mathbf{t}$ & Beta & $\mathbf{t}$ \\
\hline Sex & 01 & .69 & -02 & 1.07 & -10 & $6.07^{* *}$ & -03 & 1.87 \\
\hline Age & 00 & .20 & 04 & 2.08 & 00 & .07 & 02 & .90 \\
\hline 1. Excitable & -02 & .81 & -03 & 1.65 & -03 & 1.56 & -03 & 1.58 \\
\hline 2. Sceptical & -03 & 1.45 & 01 & .52 & 14 & $7.62^{* * *}$ & 02 & 1.08 \\
\hline 3. Cautious & 00 & .19 & 05 & $2.19^{*}$ & -18 & $8.42^{* * *}$ & 02 & .90 \\
\hline 4. Reserved & -13 & $6.59^{* * *}$ & -01 & .48 & 16 & $8.04^{* * *}$ & -03 & .30 \\
\hline 5. Leisurely & 00 & .39 & 00 & .39 & -01 & .72 & 00 & .38 \\
\hline 6. Bold & 03 & 1.28 & -02 & 1.01 & 05 & $2.71^{* *}$ & 07 & $3.54^{* * *}$ \\
\hline 8. Colourful & 13 & $5.70^{* * *}$ & 05 & $2.37^{*}$ & -02 & 1.01 & -02 & .79 \\
\hline 9. Imaginative & 00 & .34 & 01 & .47 & -07 & $3.44^{* * *}$ & -05 & $2.61^{* *}$ \\
\hline 10. Diligent & 02 & .95 & -06 & $2.89^{* *}$ & 10 & $5.34^{* * *}$ & 10 & $5.11^{* * *}$ \\
\hline 11. Dutiful & 00 & .24 & -04 & 1.89 & -11 & $5.98^{* * *}$ & -03 & 1.51 \\
\hline 12. Social Desirability & 04 & $2.22^{*}$ & 02 & .82 & -04 & $2.44^{* * *}$ & 03 & 1.87 \\
\hline$F(14,3198)=\operatorname{Adj} R^{2}$ & $13.17^{* * *}$ & .06 & $2.53^{* * *}$ & .01 & 30.69 & .12 & 10.14 & 04 \\
\hline
\end{tabular}

${ }^{* * *} p<.001 ;{ }^{* *} p<.01 ;{ }^{*} p<.05$.

The third regression onto the Thinking-Feeling (T-F) scale showed most variance accounted for. Thinking types were Sceptical, Reserved, and Diligent but Incautious and not Dutiful. They also tended to be male, and modestly high on Bold and Mischievous dimensions of the Dark side measure. Clearly it is this dimension of the MBTI that is most clearly linked to the darkside variables. The final regression with Judging-Perceiving (J-P) as the criterion variables showed Judging types are likely to be Bold and Diligent, but low on Mischievous and Imaginative.

Next, the eleven dark side variables were subjected to an or- thogonally rotated factor analysis. As has been shown many times before, three factors emerged that accounted for over fifty percent of the variance (Furnham \& Trickey, 2011). Indeed they were almost identical to that of Furnham, Trickey and Hyde (2012), who used a different data set labelled moving against, moving away from and moving towards. Following that four stepwise regressions were then computed with sex and age in the first block and the three factor scores in the second block. With the criterion variable of E-I the regression was significant $(F(5,3215)=29.86$, AdjR2 $=.04)$. This showed Introverts were more likely to move against (Beta $.14, t=8.16$, 
$p<.001$ ) but less likely to move away from others (Beta -.15 , $\mathrm{t}$ $=8.57, p<.001)$. The regression for the $\mathrm{S}-\mathrm{N}$ variables was not significant. The regression for the T-F variables was significant $(F(5,3215)=26.05$, AdjR2 $=.04)$. Those who scored high on Thinking were more likely to move against others (Beta .11, $\mathrm{t}=$ 6.49, $p<.001$ ) Away from (Beta .07, $\mathrm{t}=-4.18, p<.001$ ) but not towards (Beta $-.07, \mathrm{t}=4.05, p<.001$ ) others. The final regression with JP as the criterion variable was computed $(F(5,3215)=12.79$, AdjR2 = .02). Those who scored high on Judging were likely to score high on moving toward others (Beta .11, $\mathrm{t}=6.23, p<.001$ ) but low on moving against others (Beta $-.07, \mathrm{t}=3.92, p<.001$ ).

These regressions were then repeated with two differences. First, after sex and age were entered in the first step, the impression management scale from the HDS was then entered, followed by the eleven HDS scales. All the regressions were significant but accounted for little of the variance $(<5 \%)$. However, the regression with $\mathrm{TF}$ as the criterion scale accounted for $12 \%$ of the variance. Indeed all except two of the HDS scales were significant predictors, the most significant of which were Cautious (Beta $=-.18, \mathrm{t}=8.41, p<.001$ ), Reserved $($ Beta $=.16, \mathrm{t}=8.04, p<.001)$ and Sceptical $($ Beta $=.14$, $\mathrm{t}=7.62, p<.001)$.

A second series of regressions were then performed. Here the criterion variables were the three higher order groupings of the HDS factors. The regressions were step-wise with first sex and age being entered; then the impression management score from the HDS and finally the four MBTI scores. For the first factor "Moving Away from People" the regression was significant $(\mathrm{F}(7,3206)=24.25, p<.001$, Adj R2 = .05). Age and sex were not significant but impression management was $($ Beta $=.18, \mathrm{t}=$ $10.65, p<.001)$ and accounted for $3 \%$ of the variance. The only significant MBTI factor was EI (Beta $=-.13, \mathrm{t}=7.61, p$ $<$.001) indicating that Introverts moved away from people. The regression for the second factor "Moving Against People" was significant $(\mathrm{F}(7,3205)=25.81, p<.001$, Adj R2 = .05). The impression management factor was a significant predictor (Beta $=.10, \mathrm{t}=5.67, p<.001$ ) as were three MBTI factors: EI (Beta $=.13, \mathrm{t}=7.40, p<.001)$; TF $($ Beta $=.08, \mathrm{t}=4.67, p<.001)$ and JP $($ Beta $=-16, \mathrm{t}=9.05, p<.001)$. The regression with "Moving Towards People" as the criterion variable was significant $(\mathrm{F}(7,3206)=16.65, p<.001$; Adj R2 = .03). The impression management factor was a significant predictor $($ Beta $=.08, \mathrm{t}=$ 4.81, $p<.001$ ) as were three MBTI factors: SN (Beta $=-.04, \mathrm{t}$ $=2.17, p<.05)$; TF (Beta $=-.16, \mathrm{t}=8.94, p<.001)$ and JP $($ Beta $=.06, \mathrm{t}=3.08, p<.01)$.

\section{Discussion}

Previous studies showed that MBTI scores are logically correlated with less adaptive personality traits like Neuroticism (Furnham et al., 2003; McCrae \& Costa, 1989; MacDonald et al., 1994) as well as the personality disorders (Coolidge et al., 2001). The results seem to indicate that trait Neuroticism (measured that both the domain and facet level) was correlated most consistently with MBTI Feelings and Introversion.

This study showed a number of logical but modest, significant correlations. The three hypotheses were confirmed. The correlation results suggest that the MBTI scored Extravert has a tendency to being Bold and Colourful, and the Introvert Cautious and Reserved. Equally those classified as "Thinking Types” tended to be Sceptical, Reserved and Diligent as well as
Bold and Mischievous but not at all Cautious or Dutiful. Equally, Perceiving types were likely to be Mischievous, Colourful, Imaginative but not Diligent. Six of the dark side dimensions related to two or more MBTI factors: thus Mischievous scorers tended to be NTJ, Cautious scorers ITP, and Diligent STJ. It is however important to point out that overall the correlations were low accounting for little of the variance, though the pattern was clearer in the analysis in Table 2 compared to Table 1. In this the results suggest, as MBTI researchers insist that it is not a measure of pathology, at least of the personality disorders

Perhaps the most interesting and important part of the study lies in the regression results. Here it was apparent that while some of the dark side factors (i.e. Excitable and Leisurely) were unrelated to any of the four MBTI factors, a few (i.e. Mischievous and Diligent) were significantly related to all three. Some of the findings seem clearly interpretable. Thus MBTI Extraverts are likely to be Colourful (animated, expressive and dramatic) while Introverts may be very Reserved (aloof, detached and solitary). Judging types may be Bold (narcissistic, self-confident, arrogant) and Diligent (Self-confident, Conscientious and Perfectionistic) while Perceiving types maybe prone to being Mischievous (antisocial, adventurous) and Imaginative (adventurous, risk-taking and creative). Equally those who score very high on Thinking may be prone to being rather too Sceptical and Cynical, detached and uncommunicative, meticulous and precise, but also self-confident and adventurous.

The final set of regressions attempted to overcome some Type II errors by using the "higher order" classification of the HDS as done in other studies (Carson et al., 2012). In one set of regression the HDS factors were the independent variables and the four MBTI dimensions the dependent variables and in the other analysis this was reversed. For nearly all, the amount of incremental variance accounted for after demographic variable and impression management was small (usually less than 5\%) suggesting little overlap between these measures. Second, the results were always perfectly understandable in terms of the description of the types and traits. Thus, for instance, Introversion was associated with moving away from people.

Some reviewers of the MBTI are happy to discuss the possible "shortcomings" of a particular type. Thus Rogers (1997) notes that the common ENTJ type which is often the profile of leaders and managers lists a wide range of issues where their personal style may bring them problems: they can be overbearing, hard on what they see as unenthusiastic or self-indulgent people, over-controlling, impatient if others do not follow, very competitive, restless and demanding etc. Yet Hirsch and Kummerow (1998) paint a very different picture of the ENTJ person at work: "ENTJs are logical, organised, structured, objective and decisive about what they view as conceptually valid. They enjoy working with others, especially when they can take charge and add a strategic plan” (p. 25).

One of the disadvantages of a typological rather than a dimensional measure is loss of variance. Thus a person may be very or simply marginally extraverted to qualify as being categorised an extravert. The HDS is based on the spectrum hypothesis that suggests it is only (very) high scores that present possible risks to individuals, so it would seem much more useful for both researchers and clinicians, counsellors and trainers to use dimensional scores to get better use out of the instrument, particularly when trying to detect potential derailers. 
This study like all others had limitations. This was a large, but not a community, sample which has implications for generalisation of the data.

\section{REFERENCES}

American Psychiatric Association (1994). Diagnostic and statistical manual of mental disorders (3rd ed.). Washington DC: APA.

American Psychiatric Association (2000). Diagnostic and statistical manual of mental disorders (4th ed.). Washington DC: APA.

Bastiaansen, L., Rossi, G., Schotte, C., \& De Fruyt, F. (2011). The structure of the personality disorders. Journal of Personality Disorders, 25, 378-396. http://dx.doi.org/10.1521/pedi.2011.25.3.378

Briggs, K., \& Myers, I. (1987). Myers-Briggs type indicator form $G$. Palo Alto. CA: Consulting Psychologist Press.

Carson, M., Shanock, L., Heggestad, E., Andrew, A., Pugh, S., \& Walter, M. (2012). The relationship between dysfunctional interpersonal tendencies, derailment potential behaviour, and turnover. Journal of Business and Psychology, 27, 291-304. http://dx.doi.org/10.1007/s10869-011-9239-0

Coolidge, F. (1984). Coolidge axis II inventory. Washington DC.

Coolidge, F., Segal, D., Hook, J., Yamazaki, T., \& Elliott, J. (2001). An empirical investigation of Jung's psychological types and personality disorder features. Journal of Psychological Type, 58, 33-36.

De Clercq, B., \& De Fruyt, F. (2003). Personality disorder symptoms in adolescence: A five-factor model perspective. Journal of Personality Disorders, 17, 269-292. http://dx.doi.org/10.1521/pedi.17.4.269.23972

De Fruyt, F., De Clercq, B., Milley, J., Rolland, J. P., Jung, S. C., Taris, R., Furnham, A., \& Hiel, A. (2009). Assessing personality at risk in personnel selection and development. European Journal of Personality, 23, 51-69. http://dx.doi.org/10.1002/per.703

De Fruyt, F., Wille, B., \& Furnham, A. (2013). Assessing aberrant personality in managerial coaching. European Journal of Personality.

Fico, J., Hogan, R., \& Hogan, J. (2000). Interpersonal compass manual and interpretation guide. Tulsa, OK: Hogan Assessment System.

Furnham, A., \& Crump, J. (2005). Personality traits, types and disorders. European Journal of Personality, 19, 167-184. http://dx.doi.org/10.1002/per.543

Furnham, A. (1996). The big five versus the big four: The relationship between the Myers-Briggs Type Indicator (MBTI) and NEO-PT five factor model of personality. Personality and Individual Differences, 21, 303-307. http://dx.doi.org/10.1016/0191-8869(96)00033-5

Furnham, A. (2006). Personality disorders and intelligence. Journal of Individual Differences, 27, 42-45. http://dx.doi.org/10.1027/1614-0001.27.1.42

Furnham, A., \& Stringfield, P. (1993). Personality and occupational behaviour: Myers-Briggs type indicator correlates of management practices in two cultures. Human Relations, 46, 827-848. http://dx.doi.org/10.1177/001872679304600703

Furnham, A., \& Trickey, G. (2011). Sex differences in the dark side traits. Personality and Individual Differences, 50, 517-522. http://dx.doi.org/10.1016/j.paid.2010.11.021

Furnham, A., Hyde, G., \& Trickey, G. (2013). Do your dark side traits fit? Dysfunctional personalities in different work sectors. Applied Psychology, In Press. http://dx.doi.org/10.1111/apps.12002

Furnham, A., Moutafi, J., \& Crump, J. (2003). The relationship between the revised NEO-personality inventory and the Myers-Briggs type indicator. Social Behavior and Personality, 31, 577-584. http://dx.doi.org/10.2224/sbp.2003.31.6.577

Furnham, A., Trickey, G., \& Hyde, G. (2012). Bright aspects of dark side traits. Personality and Individual Differences, 52, 908-913. http://dx.doi.org/10.1016/j.paid.2012.01.025

Harms, P. D., Spain, S. M., \& Hannah, S. T. (2011). Leader development and the dark side of personality. Leadership Quarterly, 22,
495-509. http://dx.doi.org/10.1016/j.leaqua.2011.04.007

Hirsch, S., \& Kummerow, J. (1998). Introduction to type in organisations. Palo Alto, CA: Consulting Psychology Press.

Hogan, R., \& Hogan, J. (1997). Hogan development survey manual. Tulsa, OK: HAS.

Hogan, R., Hogan, J., \& Warrenfelz, R. (2007). The Hogan guide. Tulsa, OK: Hogan Press.

Hogan, R., \& Hogan, J. (2001). Assessing leadership: A view from the dark side. International Journal of Selection and Assessment, 9, 4051. http://dx.doi.org/10.1111/1468-2389.00162

Hogan, R. (2007). Personality and the fate of organizations. Mahwah, NJ: Lawrence Erlbaum.

Horney, K. (1950). Neurosis and human growth. New York: Norton.

Janowsky, D., Morter, S., \& Hong, L. (2002). Relationship of Myers Briggs type indicator personality characteristics to suicidality in affective disorder patients. Journal of Psychiatric Research, 36, 33-39. http://dx.doi.org/10.1016/S0022-3956(01)00043-7

Khoo, H., \& Burch, G. (2008). The "dark side” of leadership personality and transformational leadership. Personality and Individual Differences, 44, 86-97. http://dx.doi.org/10.1016/j.paid.2007.07.018

MacDonald, D., Anderson, P., Tsagarakis, C., \& Holland, J. (1994). Examination of the relationship between the Myers-Briggs type indicator and the NEO personality inventory. Psychological Reports, 74, 339-344. http://dx.doi.org/10.2466/pr0.1994.74.1.339

McCrae, R., \& Costa, P. (1989). Reinterpreting the Myers-Briggs type indicators from the perspective of the five-factor model of personality. Journal of Personality, 57, 17-40. http://dx.doi.org/10.1111/j.1467-6494.1989.tb00759.x

Morey, L., Waugh, M., \& Blashfield, R. (1985). MMPI scales for DSM-III, personality disorders: Their derivation and correlates. Journal of Personality Assessment, 49, 245-251. http://dx.doi.org/10.1207/s15327752jpa4903 5

Moscoso, S., \& Salgado, J. (2004). "Dark Side” personality scales as predictors of task, contextual, and job performance. International Journal of Selection and Assessment, 12, 356-362. http://dx.doi.org/10.1111/j.0965-075X.2004.00290.x

Myers, I., \& Myers, P. (1990). Gifts differing. Palo Alto: Consulting Psychologists Press.

Paul, A. (2004). The cult of personality. New York: Free Press

Pierson, B. (2007). Personality types and personality disorders. Unpublished Thesis, Muncie: Ball State University.

Quenk, N. (2009). Essential of Myers-Briggs type indicator assessment. Cichester: Wiley.

Rogers, J. (1997). Sixteen personality types at work in organisations. Cambridge, UK: Managers Futures.

Rolland, J. P., \& De Fruyt, F. (2003). The validity of FFM personality dimensions and maladaptive traits to predict negative affect at work. European Journal of Personality, 17, 101-121. http://dx.doi.org/10.1002/per.485

Saggino, A., \& Kline, P. (1996). The location of the Myers-Briggs type indicator in personality factor space. Personality and Individual Differences, 21, 591-597. http://dx.doi.org/10.1016/0191-8869(96)00009-8

Samuel, D., \& Widiger, T. (2008). A meta-analytic review of the relationships between the five factor model and DSM-IV-TR personality disorders. Clinical Psychology Review, 28, 1326-1342. http://dx.doi.org/10.1016/j.cpr.2008.07.002

Widiger, T. (2011). Integrating normal and abnormal personality structure. Journal of the Personality Disorders, 25, 338-363. http://dx.doi.org/10.1521/pedi.2011.25.3.338

Widiger, T., \& Coker, L. (2001). Assessing personality disorders. In J. N. Butcher (Ed.), Clinical personality assessment: Practical approaches (2nd ed., pp. 407-434). New York: Oxford University Press.

Zibarras, L., Port, R., \& Woods, S. (2008). Innovation and the "Dark Side” of personality. Journal of Creative Behaviour, 42, 201-215. http://dx.doi.org/10.1002/j.2162-6057.2008.tb01295.x 